\title{
Article \\ Effects of Cardiovagal Training on Autonomic Function, In- flammatory Markers and Insulin Levels in Adults with Obesity
}

\author{
Alexis Espinoza-Salinas, ${ }^{1,2}$, Luis Peiret-Villacura ${ }^{5}$, Edgardo Molina-Sotomayor ${ }^{3}$, Igor Cigarroa-Cuevas ${ }^{1}$, Giovanny \\ Arenas-Sánchez ${ }^{1}$, Israel Podestá ${ }^{4}$ and José González-Jurado²*
}

1 Escuela de Kinesiología, Universidad Santo Tomás, Santiago 8320000, Chile; alexisespinozasa@santotomas.cl; icigarroa@santotomas.cl; garenas2@santotomas.cl

2 Facultad de Ciencias del Deporte; Universidad Pablo de Olavide de Sevilla, 41013 Sevilla, Spain

3 Departamento de Educación Física, Facultad de Artes y Educación Física, Universidad Metropolitana de Ciencias de la Educación, Santiago 8328000, Chile; edgardo.molina@umce.cl

4 School of Sport, Exercise and Rehabilitation Sciences, College of Life and Environmental Sciences, University of Birmingham, Birmingham B15 2TT, United Kingdom; israelpodesta@gmail.com

5 Magíster en Ciencias de la Actividad Fisica y Deportes Aplicados al Entrenamiento Rehabilitación y Reintegro Deportivo, Universidad Santo Tomás, 8320000 Chile; $\underline{\text { lpeiret@santotomas.cl }}$

* Correspondence: jagonjur@upo.es ; Tel.: +34-954-977-586

\begin{abstract}
Obesity is linked to an inflammatory process, with adipocyte release triggering insulin resistance (IR) and autonomic imbalance. A cardiovagal trainning protocol has shown favorable results in autonomic balance and decrease of inflammatory markers. The aim of this study was to analyze the autonomic behavior related to inflammatory and metabolic parameters in obese people after a cardiovagal exercise protocol. Twenty people with obesity, were distributed by their HOMAIR value: obese without IR (n/IR) $(n=8)$ and obese with IR (y/IR) $(n=12)$. The cardiovagal training program was carried out in both groups for 8 weeks at a frequency of 5 times per week. A blood sample was obtained to determine insulin, leptin, TNF alpha and IL6 levels, in addition to determining the HOMA-IR index and autonomic function was measured by heart rate variability. Changes were recorded in the OB-IR group, a decrease in inflammatory markers, glycemia and a reduction of sympathetic activity after the cardiovagal training intervention. In addition, significant differences between the $y / I R$ and n/IR groups were shown in insulin, leptin, TNFa and IL6 values. It can be concluded that after 4 weeks of intervention with a cardiovagal trainning protocol, parasympathetic modulation increased and inflammatory markers decreased in obese subjects.
\end{abstract}

Keywords: obesity; high-intensity interval training; heart rate variability; inflammatory markers; insulin resistance; autonomic function.

\section{Introduction}

The great changes of lifestyle in the world population toward more sedentary behaviours have been influenced by the industrialisation and automation of society. This has triggered a progressive increase of metabolic diseases [1], with an increasing trend in the young adult population [2].

Abdominal obesity is considered to be a metabolic disorder associated with a greater rate of cardiovascular disease, insulin resistance (IR), type 2 diabetes, and alterations in the functioning of the autonomic nervous system (ANS) [3,4]. In this sense, the neural mechanisms that have been involved in the etiopathogeny of obesity and IR could be partially explained by sympathovagal imbalance, due to the fact that high sympathetic activity plays a fundamental role in this complex relationship [5].

Sedentary lifestyles, unbalanced diets and a genetic predisposition are important factors that underlie obesity; however, the evidence also indicates that the sympathetic nervous system (SNS) plays an important role in the development and progression of such 
condition [6,7]. In this line, the ANS participates in the control of the cardiovascular, respiratory, immune and endocrine systems [8,9]. Moreover, the activity of the ANS, through the sympathetic fibres that innervate the adipose tissue, stimulates the lipolysis of the latter and the vasoconstriction of the peripheral arterioles, which has been associated with the deterioration of glucose uptake by skeletal muscles [10].

One of the intervention strategies for the management of autonomic imbalance in people with obesity is the control of eating habits and physical exercise with the aim of losing weight, since weight loss is associated with an inhibition of sympathetic activity [6,11-13].

In this line, performing physical exercise regularly is associated with adaptations that favour vagal activation and reduce the sympathetic load at rest [10,14]. This modification in ANS balance has been associated with a decrease in the chronic inflammatory response, reducing the synthesis and release of pro-inflammatory cytokines [6,15,16].

One of the intervention methods through physical exercise is high-intensity interval training (HIIT), which has been described as an effective tool to modify the autonomic balance, increasing vagal activation and favouring a regression of the sympathetic activity [17-19]. From this training method, a new exercise strategy emerged, known as "vagal training", which is defined as an exercise protocol based on sudden intensity changes (low to high) [20]. This is mainly justified by the baroreceptor-modulated response linked to the high blood volume, which would trigger a great post-high-intensity cardiac ejection power $[21,22]$.

The aim of this study was to analyse the effect of a vagal exercise protocol on the inflammatory and autonomic response and compare the responses among obese people with and without IR. We proposed the hypothesis that vagal training is associated with a decrease in the inflammatory markers and with an increase in the vagal response in people with obesity.

\section{Materials and Methods}

\subsection{Participants}

The study sample consisted of 20 people of both sexes (12 men and 8 women), aged $24.1 \pm 2.15$ years, who presented obesity, determined by body mass index (BMI) $\geq 30$ (31.59 $\left.\pm 1.14 \mathrm{~kg} / \mathrm{m}^{2}\right)$. The participants were distributed into two groups, categorised by their HOMA-IR value: the group of obese without IR $(n / I R)(n=8)$ included the participants with a HOMA-IR value under 2.5, whereas the group of obese with IR (y/IR) $(n=12)$ included those with a HOMA-IR value above 2.5 (Table 1).

All participants were physically inactive $(<150$ minutes of moderate or vigorous physical activity per week). The exclusion criteria were: (i) blood pressure (BP) $\geq 130 / 85$ $\mathrm{mmHg}$, (ii) being diagnosed with some skeletal muscle, pulmonary or neurological disease that prevented them from performing the protocol of exercises, and (iii) being under treatment with some drug that affects the autonomic function. All participants signed the informed consent form, and the rules of the Declaration of Helsinki were followed throughout the study. The procedures were evaluated and authorised by the Ethics Committee of Santo Tomás University (Santiago de Chile, Chile) (CEC UST N51/2019).

\subsection{Procedures}

The study was carried out in the Physiology Laboratory of Santo Tomás University (Santiago de Chile, Chile). The participants were recruited by non-probability convenience sampling. Heart rate variability (HRV) and blood markers were measured between 8 and 10 a.m., two days before and two days after the HIIT intervention (Table 2).

Anthropometric variables. To calculate the BMI and categorise the obesity level, the height and weight of the participants were measured [23]. Waist circumference (WC) was 
recorded using an anthropometric tape (SECA - 203 ${ }^{\circledR}$, precision of $0.1 \mathrm{~cm}$ ) (Table 1), considering the middle point between the anterior superior iliac crest and the last rib as the anatomical reference [24].

Autonomic function variables. HRV was measured using a heart-rate chest strap (Polar, model $\mathrm{H} 7^{\circledR}$ ), recording the R-R intervals of the QRS complex. The data recording for the evaluation of HRV was conducted with the participants at rest, in the supine decubitus position, for 10 minutes (the first 5 minutes for the stabilisation of the $\mathrm{HR}$ and the last 5 minutes for the data recording). The room temperature $\left(22-24^{\circ} \mathrm{C}\right)$ and the noise during data recording were controlled (table 2). The data were extracted and analysed using the Kubios HRV 2.2 software (Department of Applied Physics, University of Eastern Finland, Kuopio, Finland).

Blood samples. These were obtained with the participants fasting before and immediately after the intervention by a qualified nurse, through antecubital fossa venipuncture. Blood samples $(5 \mathrm{ml})$ were gathered for the determination of glucose, insulin and the following inflammatory markers: interleukin-6 (IL-6), interleukin-10 (IL-10), tumour necrosis factor alpha (TNF- $\alpha$ ), leptin, and adiponectin (Table 2). The levels of glycemia and insulin were quantified using a clinical chemistry analyser equipment SIEMENS ADVIA 2400®. HOMA-IR was calculated with the following equation: ([fasting insulin «Uu/mL» $x$ fasting glucose «mg/dL»] / 405) [25]. This is the most reliable and frequently used method in clinical trials to evaluate changes in IR [26,27]. The value of 2.5 was considered as cut-off point to associate it with a state of IR [28,29].

The inflammatory markers were measured through ELISA (enzyme-linked immunosorbent assay) using a visible spectrophotometry equipment Iris - HI801 (HANNA INSTRUMENTS ${ }^{\circledR}$ ). Moreover, the adiponectin/leptin variable was also calculated, which is associated with the function of the adipose tissue, being a biomarker of IR and a risk factor of cardiometabolic diseases [30].

\subsection{Intervention}

A vagal training protocol was applied for 8 weeks, at a frequency of 5 times per week, using a cycle ergometer without external resistance (Monark ${ }^{\circledR}$, model Ergomedic 874E) and ergonomically adjusted to each participant. The training consisted of two phases: 1) the individual remained sitting for 55 seconds without pedaling (passive phase), and 2) the individual pedaled at maximum intensity for five seconds (active phase). The protocol consisted of 10 repetitions, with a total duration of 10 minutes. In the active phase, the individual was encouraged to carry it out at maximum intensity. As a safety and control measure during the execution of the exercise protocol, HR, BP and perceived effort were evaluated through the Borg scale. The criteria to interrupt the training protocol were the following: 1) Borg scale $>15$ (out of 20), 2) HR $>80 \%$ HRmax, and 3) systolic BP $>160$ $\mathrm{mmHG}$, diastolic BP $>100 \mathrm{mmHg}$. The test was performed indoors and it was controlled and supervised by the researchers (Figure 1). 


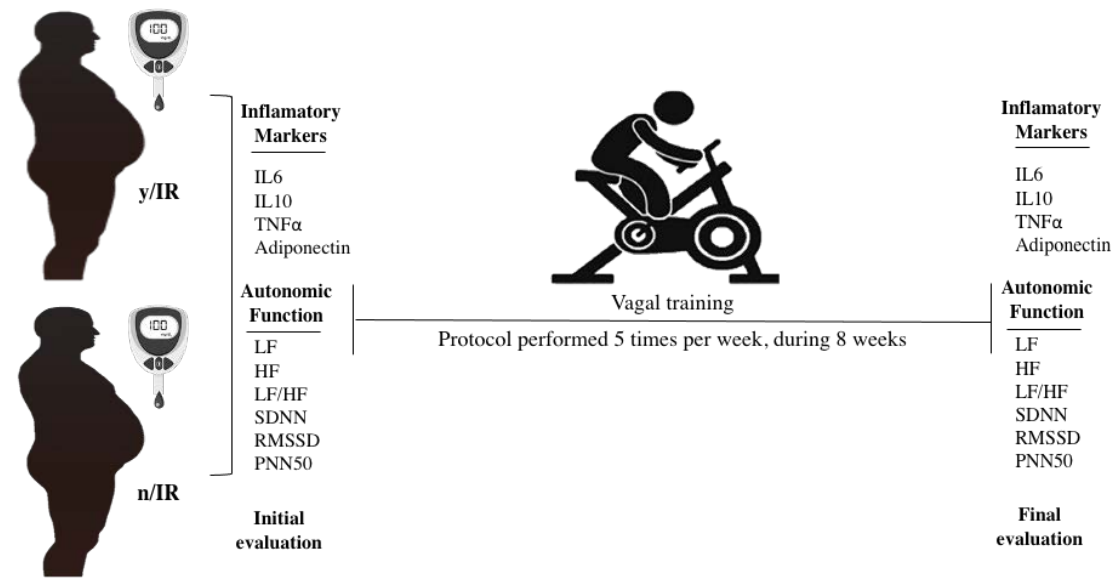

Figure 1. Training and testing exercises. n/IR (obese without insulin resistance group); $y /$ IR (obese with insulin resistance group); IL (interleukins) TNF- $\alpha$ (tumour necrosis factor alfa); LF (low frequency); HF (high frequency); LF/HF (ratio of LF-to-HF power); SDNN (standard deviation of NN intervals); RMSSD (root mean square of successive RR interval differences); PNN50 (percentage of successive RR intervals that differ by more than $50 \mathrm{~ms}$ ).

\subsection{Statistical analysis}

IBM SPSS 26® software (SPSS Inc. Chicago, IL, USA) was used for the statistical analysis. For the descriptive statistics, mean and standard error were calculated. To estimate the reliability of means, a 95\% confidence interval was calculated. Regarding inferential analysis to study the intragroup pre-post differences, Student's t-test for related samples or Wilcoxon test was conducted depending on the Shapiro-Wilk normality test (normality). The comparison between groups was performed using Student's t-test or MannWhitney U-test, depending on the normality and homoscedasticity (Levene tests). Cohen's d effect size was also calculated, considering values of $\mathrm{d}<0.3$ as small, $\mathrm{d}=0.3-0.5$ as moderate, $\mathrm{d}=0.5-0.7$ as large, $\mathrm{d}=0.7-0.9$ as very large, and $\mathrm{d}>0.9$ as extremely large. Statistical significance was set at $\mathrm{p}<0.05$.

\section{Results}

Table 1 presents the descriptive data of the study population.

Table 1. Anthropometric characteristics and insulin resistance markers of the participants.

\begin{tabular}{|c|c|c|c|c|}
\hline Variables. & $\begin{array}{c}\mathrm{n} / \mathrm{IR}(\mathrm{n}=8) \\
(\text { Mean } \pm \mathrm{SD})\end{array}$ & $\begin{array}{c}y / I R(n=12) \\
(M e a n \pm S D)\end{array}$ & p-value* & Effect Size§ \\
\hline Age (years) & $24.6 \pm 2.13$ & $23.7 \pm 2.18$ & 0.387 & 0.41 \\
\hline Weight (kg) & $92.25 \pm 4.65$ & $95.75 \pm 5.66$ & 0.164 & 0.66 \\
\hline Height (m) & $1.71 \pm 0.04$ & $1.74 \pm 0.04$ & 0.164 & 0.75 \\
\hline BMI (kg/m2) & $31.50 \pm 1.08$ & $31.67 \pm 1.21$ & 0.739 & 0.14 \\
\hline $\mathrm{WC}(\mathrm{cm})$ & $112.25 \pm 3.24$ & $121.92 \pm 4.14$ & 0.000 & 2.54 \\
\hline Insulin (uU/mL) & $10.35 \pm 0.93$ & $12.84 \pm 1.23$ & 0.000 & 1.60 \\
\hline Glucose (mg/dL) & $89.25 \pm 3.81$ & $101.83 \pm 8.14$ & 0.001 & 1.86 \\
\hline HOMA_IR & $2.27 \pm 0.12$ & $3.21 \pm 0.16$ & 0.000 & 6.46 \\
\hline
\end{tabular}

$\overline{\mathrm{n} / \mathrm{IR} \text { (obese without insulin resistance); y/IR (obese with insulin resistance); BMI (body mass index); WC (waist circumference). }{ }^{*} \mathrm{p}-}$ value: $\mathrm{t}$-test or Mann-Whitney U-test according to normality and homoscedasticity. $\S$ Cohen's $\mathrm{d}(<0.20$, trivial; $\mathrm{d}=0.2-0.6, \mathrm{small} ; \mathrm{d}=$ $0.6-1.2$, moderate; $d=1.2-2$, large; $d=2-4$, very large and $d>4$, extremely large). 
The descriptive analysis of the initial HRV shows that $y /$ IR presents the highest predominance in the sympathetic autonomic modulation for $L F(81.41 \pm 11.36 \mathrm{~Hz}$ vs $65.78 \pm$ $13.13 \mathrm{~Hz}$ ) with respect to $\mathrm{n} / \mathrm{IR}$ (Table 2). Regarding the parasympathetic modulation, $\mathrm{n} / \mathrm{IR}$ presented lower values than $y / \mathrm{IR}$ in all the variables considered: $\mathrm{HF}(20.47 \pm 4.99 \mathrm{~Hz}$ vs $21.52 \pm 4.26 \mathrm{~Hz})$, ratio LF/HF $(3.25 \pm 0.30 \mathrm{~Hz}$ vs $3.93 \pm 1.02 \mathrm{~Hz}), \operatorname{SDNN}(60.10 \pm 20.08 \mathrm{~ms}$ vs $61.27 \pm 7.07 \mathrm{~ms}), \operatorname{RMSSD}(82.16 \pm 25.74 \mathrm{~ms}$ vs. $80.60 \pm 14.07 \mathrm{~ms})$, PNN50 $(52.06 \pm 15.94 \%$ vs $53.02 \pm 6.82 \%$ ) (Table 2).

With respect to the initial inflammatory markers, $y /$ IR presented greater values in all the inflammatory markers evaluated with respect to n/IR: IL6 (2.86 \pm 0.37 vs $2.06 \pm 0.21$ $\mathrm{pg} / \mathrm{mL}), \operatorname{IL} 10(3.25 \pm 0.22$ vs $3.14 \pm 0.25 \mathrm{pg} / \mathrm{mL}), \mathrm{TNF}-\alpha(3.42 \pm 0.19$ vs $2.70 \pm 0.20 \mathrm{pg} / \mathrm{mL})$ and leptin (35.55 $\pm 1.63 \mathrm{vs} 24.26 \pm 1.14 \mathrm{ng} / \mathrm{mL}$ ) (Table 2). The adiponectin/leptin ratio in $\mathrm{y} / \mathrm{IR}$ presents lower values than $\mathrm{n} / \mathrm{IR}$ at the beginning of the intervention $(0.13 \pm 0.01 \mathrm{vs}$ $0.17 \pm 0.02)$; moreover, it was observed that, in both groups, $y / I R$ and $n / I R$ showed an increase in this variable after the intervention ( $\uparrow 31.50 \%$ vs $\uparrow 24.43 \%$, respectively) (Table 2 ).

The inflammatory markers of $\mathrm{n} / \mathrm{IR}$ showed favourable changes after the intervention: IL6 (2.06 \pm 0.21 vs $1.73 \pm 0.17 \mathrm{pg} / \mathrm{mL})$, IL10 ( $3.14 \pm 0.25$ vs $2.78 \pm 0.23 \mathrm{pg} / \mathrm{mL})$, TNF- $\alpha(2.70$ $\pm 0.20 \mathrm{vs} 2.53 \pm 0.23 \mathrm{pg} / \mathrm{mL})$, leptin $(24.26 \pm 1.14 \mathrm{vs} 23.16 \pm 1.09 \mathrm{ng} / \mathrm{mL})$, adiponectin (4.19 $\pm 0.27 \mathrm{vs} 4.96 \pm 0.23 \mathrm{ug} / \mathrm{mL})$ and adiponectin/leptin ratio $(0.17 \pm 0.02 \mathrm{vs} 0.21 \pm 0.01)$, with significant changes in all variables (Table 2 ). In $\mathrm{y} / \mathrm{IR}$, there were aksi favourable changes in the post-intervention values: IL6 ( $2.86 \pm 0.37$ vs $2.28 \pm 0.31 \mathrm{pg} / \mathrm{mL})$, IL10 $(3.25 \pm 0.22$ vs $2.59 \pm 0.26 \mathrm{pg} / \mathrm{mL}), \mathrm{TNF}-\alpha(3.42 \pm 0.19$ vs $2.77 \pm 0.26 \mathrm{pg} / \mathrm{mL})$, leptin ( $35.55 \pm 1.63$ vs $31.21 \pm$ $2.33 \mathrm{ng} / \mathrm{mL})$, adiponectin $(4.51 \pm 0.16 \mathrm{vs} 5.18 \pm 0.19 \mathrm{ug} / \mathrm{ml})$ and adiponectin/leptin ratio $(0.13 \pm 0.01$ vs $0.17 \pm 0.02)$, with significant changes in all the above mentioned variables (Table 2).

Table 2. Pre-post intragroup comparisons.

\begin{tabular}{|c|c|c|c|c|c|c|c|c|c|c|c|}
\hline & & \multicolumn{5}{|c|}{ n/IR } & \multicolumn{5}{|c|}{$\mathrm{y} / \mathrm{IR}$} \\
\hline & & $\begin{array}{c}\text { Pre } \\
\text { (Mean } \pm \\
\text { SD) }\end{array}$ & $\begin{array}{c}\text { Post } \\
\text { (Mean } \pm \\
\text { SD) }\end{array}$ & $\underset{\%}{\text { Change }}$ & $\begin{array}{c}\mathrm{p}- \\
\text { value }^{*}\end{array}$ & $\begin{array}{c}\text { Ef- } \\
\text { fect } \\
\text { size } \\
\S \\
\end{array}$ & $\begin{array}{c}\text { Pre } \\
(\text { Mean } \pm S D)\end{array}$ & $\begin{array}{c}\text { Post } \\
(\text { Mean } \pm \text { SD) }\end{array}$ & $\begin{array}{c}\text { Change } \\
\%\end{array}$ & $\begin{array}{c}\mathrm{p}- \\
\text { value }^{*}\end{array}$ & $\begin{array}{c}\text { Ef- } \\
\text { fect } \\
\text { size§ }\end{array}$ \\
\hline \multirow{6}{*}{$\begin{array}{l}\text { Inflammatory } \\
\text { Markers }\end{array}$} & $\begin{array}{c}\text { IL6 } \\
\text { (pg/mL) }\end{array}$ & $2.06 \pm 0.21$ & $1.73 \pm 0.17$ & $\downarrow 16.03$ & 0.001 & 1.94 & $2.86 \pm 0.37$ & $2.28 \pm 0.31$ & $\downarrow 20.38$ & $<0.001$ & 1.87 \\
\hline & $\begin{array}{c}\text { IL10 } \\
(\mathrm{pg} / \mathrm{mL})\end{array}$ & $3.14 \pm 0.25$ & $2.78 \pm 0.23$ & $\downarrow 11.41$ & 0.001 & 1.56 & $3.25 \pm 0.22$ & $2.59 \pm 0.26$ & $\downarrow 20.30$ & $<0.001$ & 2.53 \\
\hline & $\begin{array}{c}\text { TNF- } \alpha \\
(\mathrm{pg} / \mathrm{mL})\end{array}$ & $2.70 \pm 0.20$ & $2.53 \pm 0.23$ & $\downarrow 6.51$ & 0.004 & 0.73 & $3.42 \pm 0.19$ & $2.77 \pm 0.26$ & $\downarrow 19.11$ & $<0.001$ & 2.5 \\
\hline & $\begin{array}{l}\text { Leptin } \\
\text { (ng/ml) }\end{array}$ & $24.26 \pm 1.14$ & $23.16 \pm 1.09$ & $\downarrow 4.50$ & 0.003 & 1.0 & $35.55 \pm 1.63$ & $31.21 \pm 2.33$ & $\downarrow 12.16$ & $<0.001$ & 1.86 \\
\hline & $\begin{array}{l}\text { Adiponectin } \\
\quad(\mathrm{ug} / \mathrm{dL})\end{array}$ & $4.19 \pm 0.27$ & $4.96 \pm 0.23$ & $\uparrow 18.71$ & $<0.001$ & 3.34 & $4.51 \pm 0.16$ & $5.18 \pm 0.19$ & $\uparrow 15.00$ & $<0.001$ & 3.52 \\
\hline & Adip/Leptin & $0.17 \pm 0.02$ & $0.21 \pm 0.01$ & $\uparrow 24.43$ & $<0.001$ & 4.0 & $0.13 \pm 0.01$ & $0.17 \pm 0.02$ & $\uparrow 31.50$ & $<0.001$ & 2.0 \\
\hline \multirow{6}{*}{$\begin{array}{l}\text { Heart rate } \\
\text { variability }\end{array}$} & SDNN & $60.10 \pm 20.08$ & $65.25 \pm 20.96$ & $\uparrow 9.07$ & 0.004 & 0.24 & $61.27 \pm 7.07$ & $80.14 \pm 9.41$ & $\uparrow 31.30$ & $<0.001$ & 2.0 \\
\hline & RMSSD & $82.16 \pm 25.74$ & $91.52 \pm 26.09$ & $\uparrow 12.4$ & $<0.001$ & 0.35 & $80.60 \pm 14.07$ & $100.43 \pm 18.49$ & $\uparrow 25.67$ & $<0.001$ & 1.07 \\
\hline & PNN50 & $52.06 \pm 15.94$ & $55.49 \pm 16.52$ & $\uparrow 6.76$ & 0.002 & 0.20 & $53.02 \pm 6.82$ & $66.98 \pm 6.92$ & $\uparrow 27.34$ & $<0.001$ & 2.01 \\
\hline & LF & $65.78 \pm 13.13$ & $56.29 \pm 13.30$ & $\downarrow 14.78$ & 0.002 & 0.71 & $81.41 \pm 11.36$ & $70.27 \pm 12.26$ & $\downarrow 14.05$ & $<0.001$ & 0.90 \\
\hline & $\mathrm{HF}$ & $20.47 \pm 4.99$ & $23.21 \pm 5.72$ & $\uparrow 13.29$ & $<0.001$ & 0.47 & $21.52 \pm 4.26$ & $31.61 \pm 7.26$ & $\uparrow 48.03$ & $<0.001$ & 1.38 \\
\hline & $\mathrm{LF} / \mathrm{HF}$ & $3.25 \pm 0.30$ & $2.44 \pm 0.29$ & $\downarrow 24.7$ & $<0.001$ & 2.79 & $3.93 \pm 1.02$ & $2.35 \pm 0.77$ & $\downarrow 40.06$ & $<0.001$ & 2.05 \\
\hline
\end{tabular}

$\mathrm{n} / \mathrm{IR}$ Group (obese without insulin resistance); y/IR Group (obese with insulin resistance). Change \% (percentage change between $\mathrm{n} / \mathrm{IR}$ and y/IR pre and post intervention)IL (interleukins) TNF- $\alpha$ (Tumour Necrosis Factor alfa); LF (low frequency); HF (high frequency); LF/HF (ratio of LF-to-HF power); SDNN (standard deviation of NN intervals); RMSSD (root mean square of successive RR interval differences); PNN50 (percentage of successive RR intervals that differ by more than $50 \mathrm{~ms}$ ). ${ }^{*} \mathrm{p}$-value: $\mathrm{t}$-test or Wilcoxon according to normality. §Cohen's $\mathrm{d}(<0.20$, trivial; $\mathrm{d}=0.2-0.6$, small; $\mathrm{d}=0.6-1.2$, moderate; $\mathrm{d}=1.2-2$, large; $\mathrm{d}=2-4$, very large)

In n/IR, HRV showed favourable changes: SDNN $(60.10 \pm 20.08$ vs $65.25 \pm 20.93 \mathrm{~ms})$, $\operatorname{RMSSD}(82.16 \pm 25.74$ vs $91.52 \pm 26.09 \mathrm{~ms})$, PNN50 (52.06 \pm 15.94 vs $55.49 \pm 16.52 \%)$, LF $(67.78 \pm 13.13 \mathrm{~Hz}$ vs $56.29 \pm 13.30 \mathrm{~Hz}), \mathrm{HF}(20.47 \pm 4.99 \mathrm{vs} 23.21 \pm 5.72 \mathrm{~Hz})$, and LF/HF ratio 
( $3.25 \pm 0.30$ vs $2.44 \pm 0.29 \mathrm{~Hz}$ ), with significant changes in the variables RMSSD, HF and $\mathrm{LF} / \mathrm{HF}$ ratio (Table 2). Similarly, in y/IR, there were also favourable changes in the postintervention values: SDNN (61.27 \pm 7.07 vs $80.14 \pm 9.41 \mathrm{~ms})$, RMSSD $(80.60 \pm 14.07$ vs 100.43 $\pm 18.49 \mathrm{~ms})$, PNN50 (53.02 \pm 6.82 vs $66.98 \pm 6.92 \%)$, LF $(81.41 \pm 11.36 \mathrm{~Hz}$ vs $70.27 \pm 12.26$ $\mathrm{Hz}), \mathrm{HF}(21.52 \pm 4.26$ vs $31.61 \pm 7.26 \mathrm{~Hz})$, and $\mathrm{LF} / \mathrm{HF}$ ratio $(3.93 \pm 1.02$ vs $2.35 \pm 0.77 \mathrm{~Hz})$. All changes were statistically significant (Table 2).

Figures 2 and 3 compare the differences between groups in the pre-post changes for the inflammatory markers and HRV, respectively. Regarding the inflammatory markers, there were significant differences in the change percentages between the two groups. In $\mathrm{y} / \mathrm{IR}$, there were greater changes in the levels of IL6 $(0.25 \mathrm{pg} / \mathrm{mL}), \operatorname{IL} 10(0.30 \mathrm{pg} / \mathrm{mL})$, and TNF- $\alpha(0.48 \mathrm{pg} / \mathrm{mL})$. Leptin presented a greater decrease $(3.24 \mathrm{ng} / \mathrm{mL})$ with respect to $\mathrm{n} / \mathrm{IR}$. The change differences between groups showed important modifications in the inflammatory markers: IL-6 ( $\mathrm{p}=0.002)$, IL-10 ( $\mathrm{p}=0.002)$, TNF- $\alpha(\mathrm{p}=0.001)$ and leptin ( $\mathrm{p}=0.001)$.
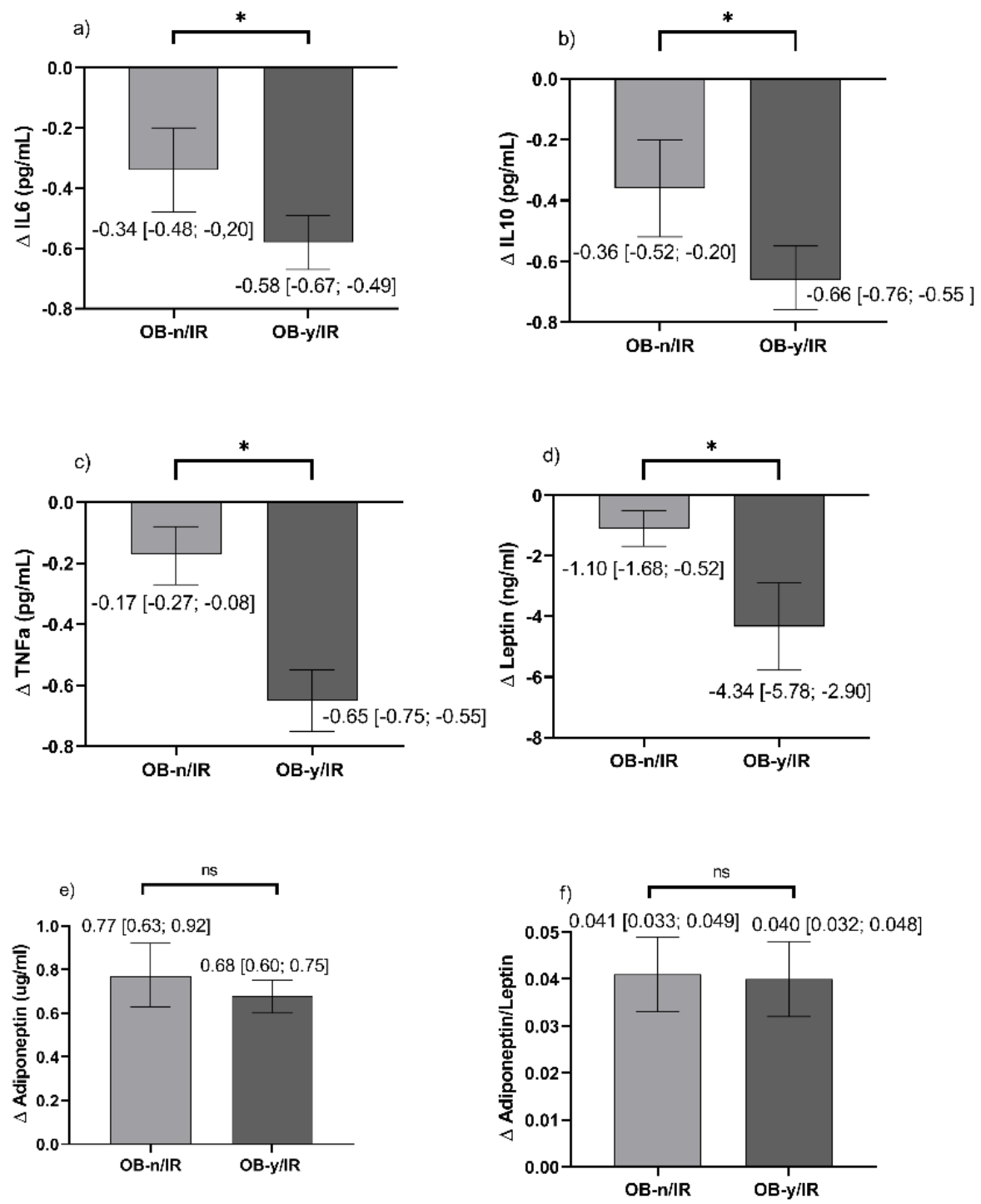

Figure 2. Difference of inflammatory markers between $y / I R$ and n/IR groups. (a): exchange rate IL6 (interleukins); (b) exchange rate IL10 (interleukins); (c) exchange rate TNF- $\alpha$ (Tumour Necrosis Factor alfa); (d) exchange rate leptin; (e) exchange rate adiponeptin; (f) exchange rate adiponeptin/leptin

* Significant differences between groups ( $p<0.05)$; ns: no significant differences $(p>0.05)$. 
In regard to the HRV variables, y/IR presented greater changes in SDNN (-13.72), PNN50 (-10.53) and HF (-7.35), with LF/HF showing a greater decrease (0.77); the change differences were significant in PNN50 $(\mathrm{p}=0.001), \mathrm{HF}(\mathrm{p}=0.001)$ and LF/HF $(\mathrm{p}=0.001)$. On the other hand, the values of RMSSD $(\mathrm{p}=0.052)$ and LF $(\mathrm{p}=0.402)$ did not present significant changes, although they showed greater changes in OB-y/IR (Figure 3).
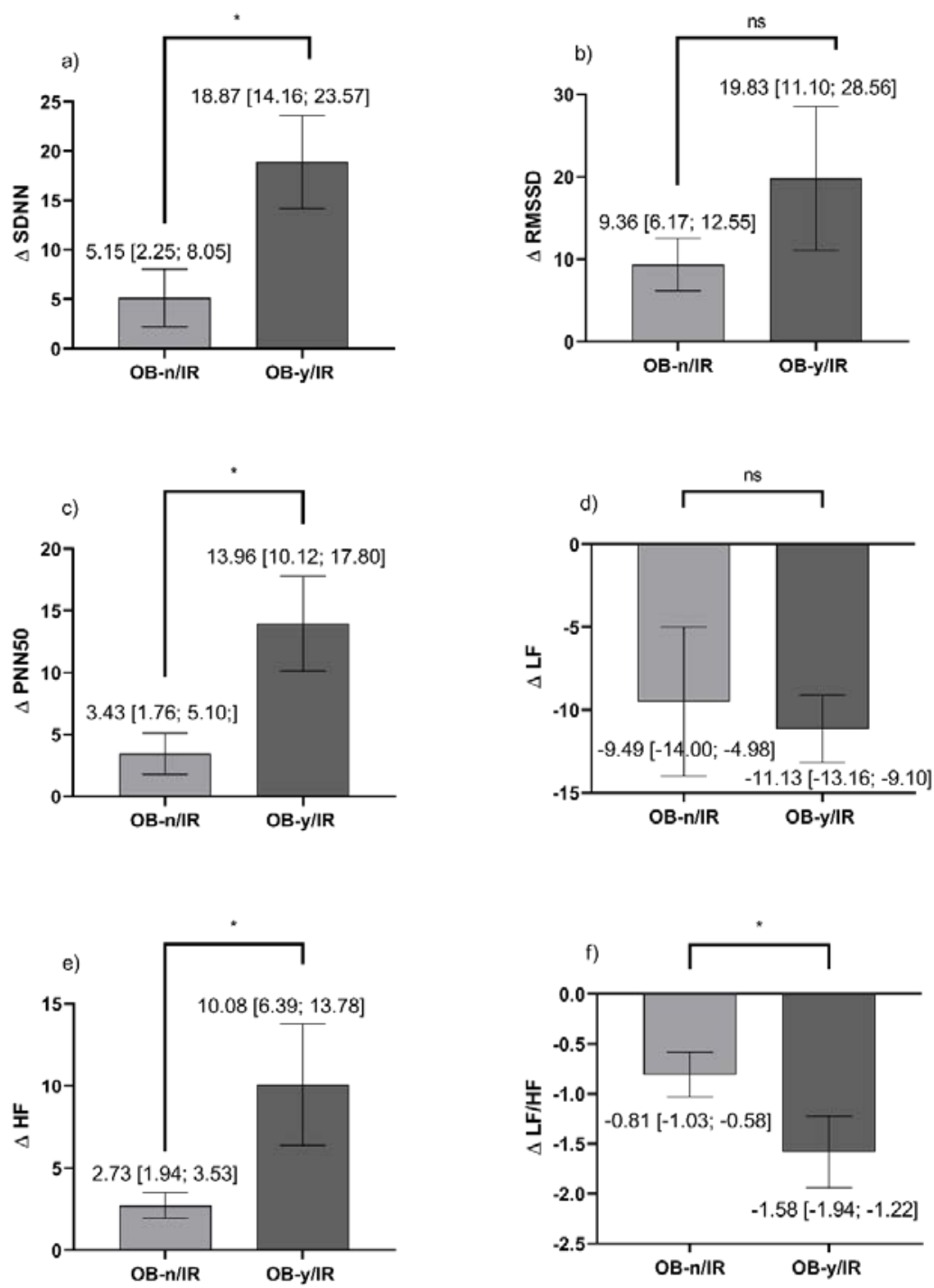

Figure 3. Difference of HRV parameters in frequency and time domain between $y / I R$ and $n / I R$ groups. (a) exchange rate SDNN (standard deviation of NN intervals); (b) exchange rate RMSSD (root mean square of successive RR interval differences); (c) exchange rate PNN50 (percentage of successive RR intervals that differ by more than $50 \mathrm{~ms}$ ); (d) exchange rate LF (low frequency); (e) exchange rate HF (high frequency); (f) exchange rate LF/HF (ratio of LF-to-HF power).

* Significant differences between groups $(\mathrm{p}<0.05)$; ns: no significant differences $(\mathrm{p}>0.05)$.

\section{Discussion}

This study was focused on analyzing the effect of a vagal exercise protocol on the inflammatory and autonomic response in people with obesity.

Sympathetic nervous activation affects relevant aspects of the physiopathology of obesity and its metabolic effects. However, the mechanisms involved in this relationship remain unclear, since most of them present a bidirectional effect. For example, IR may be caused by the sympathetic activation, although, in turn, the associated hyperinsulinemia may activate the sympathetic branch of the ANS [5]. 
The data obtained in this study show that people with obesity and IR present greater sympathetic activity at rest, accompanied by a greater presence of inflammatory markers (Table 2). This could be explained by an imbalance in inflammatory signaling [31], triggering a state of low-grade chronic inflammation; consequently, immune cells infiltrate, altering the structure and function of the adipose tissue [32]. In this sense, the effects of abdominal obesity should not be focused only on the change in body composition, but also on the potential impact on the physiopathology of the metabolic syndrome [3]. Thus, with the presence of morphofunctional changes, different types of obesity profiles are recognised, as was observed in our study, which identified a group of participants with obesity and no metabolic response (n/IR) and a group of participants with obesity who were metabolically active (y/RI) (Table 2).

Weight loss and physical exercise are key treatments in the control of obesity and metabolic syndrome. In this line, the reduction of visceral fat is linked to weight loss. One of the methods to favor weight loss is physical exercise in its high-intensity modality, which, in turn, is associated with a decrease in sympathetic nervous activity. In this sense, the scientific evidence highlights the benefits of HIIT in people with obesity in relation to weight composition [33], the reduction of inflammatory markers [34] and the decrease of the sympathetic response [35]. Furthermore, HIIT has been recognised as an effective tool for the treatment of obesity, not only for its improvements in health parameters (Sawyer et al. 2016) but also for its adherence, as it is a time-effective modality [36].

In line with the results of Khalafi and Symonds [34], out findings show a decrease in the inflammatory markers (IL-6, IL-10, TNF- $\alpha$ ) and leptin after the exercise protocol, along with an increase in the levels of adiponectin, with greater changes for $y / I R$, (Figure 2). Although the physiological mechanisms are not fully understood, some studies have shown the anti-inflammatory effect of HIIT. For instance, in the meta-analysis of Khalafi et al. (2020), 29 scientific studies (84 participants) demonstrated that, after a physical exercise protocol, there was a decrease in inflammatory markers and leptin, and an increase in adiponectin. However, IL-6 did not show a decrease in its parameters [34]. Similar results have also been obtained by Santos et al. (2016) [37], who evaluated the effect of a 16week exercise protocol on inflammatory markers (IL- 6, IL-10, TNF- $\alpha$ and adiponectin) and insulin in 32 people with obesity and overweight. Of the two groups of participants, one performed a treadmill-training protocol 3 times per week of HIIT $1 \times 4$ min at $90 \%$ HRmax, whereas the other group performed continuous strain at $70 \%$ HRmax. At the end of the training, the values of IL-6 and adiponectin decreased only in the HIIT group $(\mathrm{P}=0.035)$ [37]. In this line, it has been reported that a concurrent 8-week training (three times per week) significantly increased the levels of the adiponectin/leptin index in both men $(+63.5 \%)$ and women with obesity $(+59.2 \%)[38]$.

In addition to the abovementioned, HIIT could generate modifications in the autonomic response, through changes in vagal activity. This could be explained by the effect of the transitions of high and low intensity, which would be associated with an increase of the central blood volume, resulting in a greater ejection volume. This greater ejection volume, after being detected by the arterial and/or carotid baroreceptors, would send a signal to the central nervous system, which would trigger a sympathetic retreat and a vagal activation during the recovery phase [21,22]. Thus, this study obtained a decrease in the sympathetic response (LF) and an increase of all variables related to the parasympathetic response (temporal variables SDNN, RMSSD, PNN50 and frequency variables $\mathrm{HF}$ and LF/HF) (Table 2). Similar results have been reported in the study of Silva et al. (2019) [39], in which 10 individuals completed three protocols: 1) a 30:30 HIIT (29 repetitions of 30 seconds each at 100\% VO2max), 2) a 4:3 HIIT (3 repetitions of 4 minutes each at $90 \% \mathrm{VO} 2 \mathrm{max}$ ), and 3) a continuous moderate-intensity protocol (21 minutes at $70 \%$ VO2max). Of the 3 protocols, HIIT 4:3 showed significant improvements in the linear variables related to the vagal response (greater sympathetic modulation of HF and lower parasympathetic modulation of LF) [39]. In the same line, Duarte et al. (2013) [20,40] con- 
ducted an 8-week study applying a protocol 3 times per week to 44 participants who performed a vagal training in a cycle ergometer ( 5 repetitions of 5 seconds each at maximum speed without load, with 55 seconds of rest between repetitions). The mentioned study obtained improvements in the vagal tone after the applied protocol [20]. At the beginning of the exercise, an immediate decrease of the vagal tone was observed, with an increase in cardiac output and HR during the first the seconds; then, when the high intensity was over, there was an overload of volume/pressure in the carotid bodies and baroreflex activation. With a training period of multiple repetitions, the reeducation of the reflex arc returns to the vagal activation induced by exercise. Immediately after the exercise protocol, the HR kinetics show a biphasic behaviour [20,40], characterised by a rapid decrease due to an increase in vagal activity, followed by a second, longer phase of HR decrease due to a slow sympathetic-adrenal retreat [40].

Similarly, HIIT could also explain the decrease in visceral fat. It has been reported that HIIT is more effective in weight loss than continuous aerobic exercise [41,42], which plays an important role in the regulation of body composition and the local consumption of fat. HIIT promotes the secretion of catecholamines, adrenaline [43], noradrenaline [44] and growth hormone, favouring the use of fat [45] to attain an effective weight loss.

Furthermore, the inflammatory, autonomic and WC values were greater in y/IR (Table 1). This could be due to the fact that the increase of central obesity increases fat mass through hypertrophy, resulting in a structural and functional remodeling, thus promoting a mild chronic inflammatory process, mainly at the expense of a change in the state of macrophages toward a pro-inflammatory state $[46,47]$. As a result of this, the infiltration of macrophages is responsible for the secretion of pro-inflammatory cytokines. The secretion of TNF- $\alpha$ plays an important role in the development of IR [48,49], affecting the insulin sensitivity of adipocytes through alterations in the signaling pathways and due to a functional and structural decrease in insulin receptor substrate (IRS) proteins, which results in a state of hyperinsulinemia due to the lack of hypoglycemic capacity [50].

It has been hypothesised that peripheral signals transmitted by insulin reach they hypothalamus and are associated with the activation of the proopiomelanocortin (POMC) pathway, which, in turn, activates melanocortin receptors (MC4) [3]. The activation of melanocortin receptor MC4 modulates the peripheral sympathetic activation, presumably through direct and indirect signaling processes. However, the current evidence suggests that the activation of the autonomic load from the reticular formation in the brain stem depends on a metabolic pathway associated with IRS-2 and PI3K [50, 51]. Thus, it is considered that the increase of TNF- $\alpha$ in blood causes a failure in the intracellular signaling of the sympathetic and parasympathetic efferent neurons of the brain stem, increasing the heart and kidney sympathetic discharge [52]. However, on the other hand, the increase in adipose tissue generates a great concentration of leptin, which contributes to sympathetic activation and the development of IR in people with obesity [53]. High levels of leptin are strongly related to the activation of the renal sympathetic system, which is caused by changes that take place in neural signaling [3]. Therefore, with the increase of inflammatory markers and leptin, there is a change in the sympathetic response [5].

Two limitations of this study are the small sample size and the short duration of the intervention. A longer training programme would produce more consistent information about the stability of these responses to this type of training.

\section{Conclusions}

The results of this study indicate that, after 8 weeks of cardiovagal training, there was a decrease in the inflammatory markers and a better vagal response in people with obesity. Similarly, the group of obese people with insulin resistance showed a greater response to the vagal training protocol than the group of obese people without insulin resistance. 


\begin{abstract}
Author Contributions: Conceptualization, A.E.-S. and J.G.-J.; methodology, A.E.-S, I.C.C.; formal analysis, I.C.C; investigation, A.E.-S., I.P., L.P.-V. resources, A.E.-S. and J.G.-J.; writing-original draft preparation, A.E.-S., L.P.-V.; writing - review and editing, A.E.-S, J.G.-J., E.M.-S. All authors have read and agreed to the published version of the manuscript.
\end{abstract}

Funding: This research received no external funding.

Institutional Review Board Statement: The study was conducted according to the guidelines of the Declaration of Helsinki and approved by the Ethics Committee of University of Santo Tomás de Santiago de Chile (CEC UST No51/2019), data of approval: 27 November 2019)

Informed Consent Statement: Informed consent was obtained from all subjects involved in the study

Data Availability Statement: The data presented in this study are available on request from the corresponding author. The data are not publicly available due to privacy.

Acknowledgments: In this section, you can acknowledge any support given which is not covered by the author contribution or funding sections. This may include administrative and technical support, or donations in kind (e.g., materials used for experiments).

Conflicts of Interest: The authors declare no conflict of interest.

\title{
References
}

1. Lee, J. Influences of Cardiovascular Fitness and Body Fatness on the Risk of Metabolic Syndrome: A Systematic Review and Meta-Analysis. Am. J. Health Promot. 2020, 34.

2. Han, E.; Powell, L.M. Effect of Food Prices on the Prevalence of Obesity among Young Adults. Public Health 2011, 125, 129135.

3. Schlaich, M.; Straznicky, N.; Lambert, E.; Lambert, G. Metabolic Syndrome: A Sympathetic Disease? The Lancet Diabetes \& Endocrinology 2015, 3, 148-157.

4. Alberti, K.G.M.M.; Zimmet, P.; Shaw, J.; IDF Epidemiology Task Force Consensus Group The Metabolic Syndrome--a New Worldwide Definition. Lancet 2005, 366, 1059-1062.

5. Russo, B.; Menduni, M.; Borboni, P.; Picconi, F.; Frontoni, S. Autonomic Nervous System in Obesity and Insulin-ResistanceThe Complex Interplay between Leptin and Central Nervous System. International Journal of Molecular Sciences 2021, $22,5187$.

6. Strüven, A.; Holzapfel, C.; Stremmel, C.; Brunner, S. Obesity, Nutrition and Heart Rate Variability. Int. J. Mol. Sci. $2021,22$.

7. Miller, C.T.; Fraser, S.F.; Selig, S.E.; Rice, T.; Grima, M.; van den Hoek, D.J.; Ika Sari, C.; Lambert, G.W.; Dixon, J.B. Fitness, Strength and Body Composition during Weight Loss in Women with Clinically Severe Obesity: A Randomised Clinical Trial. Obes. Facts 2020, 1-15.

8. Browning, K.N.; Verheijden, S.; Boeckxstaens, G.E. The Vagus Nerve in Appetite Regulation, Mood, and Intestinal Inflammation. Gastroenterology 2017, 152, 730-744.

9. Chobanyan-Jürgens, K.; Jordan, J. Autonomic Nervous System Activity and Inflammation: Good Ideas, Good Treatments, or Both? Am. J. Physiol. Heart Circ. Physiol. 2015, 309, H1999-H2001.

10. Saxton, S.N.; Withers, S.B.; Heagerty, A.M. Emerging Roles of Sympathetic Nerves and Inflammation in Perivascular Adipose Tissue. Cardiovasc. Drugs Ther. 2019, 33, 245-259.

11. Lambert, G.W.; Schlaich, M.P.; Eikelis, N.; Lambert, E.A. Sympathetic Activity in Obesity: A Brief Review of Methods and Supportive Data. Ann. N. Y. Acad. Sci. 2019, 1454, 56-67.

12. Costa, J.; Moreira, A.; Moreira, P.; Delgado, L.; Silva, D. Effects of Weight Changes in the Autonomic Nervous System: A Systematic Review and Meta-Analysis. Clin. Nutr. 2019, 38, 110-126.

13. Straznicky, N.E.; Lambert, E.A.; Lambert, G.W.; Masuo, K.; Esler, M.D.; Nestel, P.J. Effects of Dietary Weight Loss on Sympathetic Activity and Cardiac Risk Factors Associated with the Metabolic Syndrome. J. Clin. Endocrinol. Metab. 2005, 90, 59986005.

14. Straznicky, N.E.; Grima, M.T.; Sari, C.I.; Eikelis, N.; Lambert, G.W.; Nestel, P.J.; Karapanagiotidis, S.; Wong, C.; Richards, K.; Marusic, P.; et al. A Randomized Controlled Trial of the Effects of Pioglitazone Treatment on Sympathetic Nervous System Activity and Cardiovascular Function in Obese Subjects with Metabolic Syndrome. J. Clin. Endocrinol. Metab. 2014, 99, E1701E1707.

15. Besnier, F.; Labrunée, M.; Pathak, A.; Pavy-Le Traon, A.; Galès, C.; Sénard, J.-M.; Guiraud, T. Exercise Training-Induced Modification in Autonomic Nervous System: An Update for Cardiac Patients. Ann. Phys. Rehabil. Med. 2017, 60, $27-35$.

16. Johnston, G.R.; Webster, N.R. Cytokines and the Immunomodulatory Function of the Vagus Nerve. Br. J. Anaesth. 2009, 102, $453-462$. 
17. Besnier, F.; Labrunée, M.; Richard, L.; Faggianelli, F.; Kerros, H.; Soukarié, L.; Bousquet, M.; Garcia, J.-L.; Pathak, A.; Gales, C.; et al. Short-Term Effects of a 3-Week Interval Training Program on Heart Rate Variability in Chronic Heart Failure. A Randomised Controlled Trial. Ann. Phys. Rehabil. Med. 2019, 62, 321-328.

18. Raffin, J.; Barthélémy, J.-C.; Dupré, C.; Pichot, V.; Berger, M.; Féasson, L.; Busso, T.; Da Costa, A.; Colvez, A.; Montuy-Coquard, C.; et al. Exercise Frequency Determines Heart Rate Variability Gains in Older People: A Meta-Analysis and Meta-Regression. Sports Med. 2019, 49, 719-729.

19. Guiraud, T.; Nigam, A.; Gremeaux, V.; Meyer, P.; Juneau, M.; Bosquet, L. High-Intensity Interval Training in Cardiac Rehabilitation. Sports Med. 2012, 42, 587-605.

20. Duarte, C.; Castro, C.; Araujo, C. Treinamento Para Disfunção Vagal Cardíaca Com Repetições Da Transição Repouso-Exercício. Rev Bras Ativ Fis Saude 2013, 18.

21. White, D.W.; Raven, P.B. Autonomic Neural Control of Heart Rate during Dynamic Exercise: Revisited. J. Physiol. 2014, 592, 2491-2500.

22. Borresen, J.; Lambert, M.I. Autonomic Control of Heart Rate during and after Exercise : Measurements and Implications for Monitoring Training Status. Sports Med. 2008, 38, 633-646.

23. Body Mass Index - BMI. 2020.

24. Waninge, A.; Ligthart, K.A.M.; Kramer, J.; Hoeve, S.; van der Schans, C.P.; Haisma, H.H. Measuring Waist Circumference in Disabled Adults. Res. Dev. Disabil. 2010, 31, 839-847.

25. Acosta B, A.M.; Escalona O, M.; Maiz G, A.; Pollak C, F.; Leighton P, F. Determinación Del índice de Resistencia Insulínica Mediante HOMA En Una Población de La Región Metropolitana de Chile. Rev. Med. Chil. 2002, 130.

26. Kurtoğlu, S.; Hatipoğlu, N.; Mazıcıoğlu, M.; Kendirici, M.; Keskin, M.; Kondolot, M. Insulin Resistance in Obese Children and Adolescents: HOMA-IR Cut-off Levels in the Prepubertal and Pubertal Periods. J. Clin. Res. Pediatr. Endocrinol. 2010, 2, 100106.

27. Wallace, T.M.; Matthews, D.R. The Assessment of Insulin Resistance in Man. Diabet. Med. $2002,19$.

28. Sochol, K.M.; Johns, T.S.; Buttar, R.S.; Randhawa, L.; Sanchez, E.; Gal, M.; Lestrade, K.; Merzkani, M.; Abramowitz, M.K.; Mossavar-Rahmani, Y.; et al. The Effects of Dairy Intake on Insulin Resistance: A Systematic Review and Meta-Analysis of Randomized Clinical Trials. Nutrients 2019, 11.

29. Radikova, Z.; Koska, J.; Huckova, M.; Ksinantova, L.; Imrich, R.; Vigas, M.; Trnovec, T.; Langer, P.; Sebokova, E.; Klimes, I. Insulin Sensitivity Indices: A Proposal of Cut-off Points for Simple Identification of Insulin-Resistant Subjects. Exp. Clin. Endocrinol. Diabetes 2006, 114.

30. Frühbeck, G.; Catalán, V.; Rodríguez, A.; Gómez-Ambrosi, J. Adiponectin-Leptin Ratio: A Promising Index to Estimate Adipose Tissue Dysfunction. Relation with Obesity-Associated Cardiometabolic Risk. Adipocyte 2018, 7, 57.

31. Cai, D.; Khor, S. "Hypothalamic Microinflammation” Paradigm in Aging and Metabolic Diseases. Cell Metab. $2019,30$.

32. Saltiel, A.R.; Olefsky, J.M. Inflammatory Mechanisms Linking Obesity and Metabolic Disease. J. Clin. Invest. $2017,127$.

33. Wewege, M.; van den Berg, R.; Ward, R.E.; Keech, A. The Effects of High-Intensity Interval Training vs. Moderate-Intensity Continuous Training on Body Composition in Overweight and Obese Adults: A Systematic Review and Meta-Analysis. Obes. Rev. 2017, 18.

34. Khalafi, M.; Symonds, M.E. The Impact of High-Intensity Interval Training on Inflammatory Markers in Metabolic Disorders: A Meta-Analysis. Scand. J. Med. Sci. Sports 2020, 30.

35. Gladwell, V.F.; Sandercock, G.R.; Birch, S.L. Cardiac Vagal Activity Following Three Intensities of Exercise in Humans. Clin. Physiol. Funct. Imaging 2010, 30.

36. Vella, C.A.; Taylor, K.; Drummer, D. High-Intensity Interval and Moderate-Intensity Continuous Training Elicit Similar Enjoyment and Adherence Levels in Overweight and Obese Adults. EJSS 2017, 17.

37. Santos, C.C.; Diniz, T.A.; Inoue, D.S.; Gerosa-Neto, J.; Panissa, V.L.G.; Pimentel, G.D.; Campos, E.Z.; Hofmann, P.; Lira, F.S. Influence to High-Intensity Intermittent and Moderate-Intensity Continuous Exercise on Indices of Cardio-Inflammatory Health in Men. Eur. J. Cardiovasc. Prev. Rehabil. 2016, 12, 618.

38. González-Jurado, J.A.; Suárez-Carmona, W.; López, S.; Sánchez-Oliver, A.J. Changes in Lipoinflammation Markers in People with Obesity after a Concurrent Training Program: A Comparison between Men and Women. Int. J. Environ. Res. Public Health 2020, 17.

39. Silva, L.R.B.; Gentil, P.R.V.; Beltrame, T.; Basso Filho, M.A.; Alves, F.M.; Silva, M.S.; Pedrino, G.R.; Ramirez-Campillo, R.; Coswig, V.; Rebelo, A.C.S. Exponential Model for Analysis of Heart Rate Responses and Autonomic Cardiac Modulation during Different Intensities of Physical Exercise. R Soc Open Sci 2019, 6, 190639.

40. Espinoza-Salinas, A.; González-Jurado, J.; Burdiles-Alvarez, A.; Arenas-Sanchez, G.; Bobadilla, M. Efectos Del Entrenamiento Cardiovagal En La Respuesta Autonómica En Personas Con Sobrepeso (Effects of Cardiovagal Training on Autonomic Response in Overweight People). Retos digit. 2019, 118-122.

41. Cheema, B.S.; Davies, T.B.; Stewart, M.; Papalia, S.; Atlantis, E. The Feasibility and Effectiveness of High-Intensity Boxing Training versus Moderate-Intensity Brisk Walking in Adults with Abdominal Obesity: A Pilot Study. BMC Sports Sci. Med. Rehabil. $2015,7,3$.

42. Keating, S.E.; Machan, E.A.; O’Connor, H.T.; Gerofi, J.A.; Sainsbury, A.; Caterson, I.D.; Johnson, N.A. Continuous Exercise but Not High Intensity Interval Training Improves Fat Distribution in Overweight Adults. J. Obes. 2014, 2014. 
43. Williams, C.B.; Zelt, J.G.; Castellani, L.N.; Little, J.P.; Jung, M.E.; Wright, D.C.; Tschakovsky, M.E.; Gurd, B.J. Changes in Mechanisms Proposed to Mediate Fat Loss Following an Acute Bout of High-Intensity Interval and Endurance Exercise. Appl. Physiol. Nutr. Metab. 2013, 38.

44. Peake, J.M.; Tan, S.J.; Markworth, J.F.; Broadbent, J.A.; Skinner, T.L.; Cameron-Smith, D. Metabolic and Hormonal Responses to Isoenergetic High-Intensity Interval Exercise and Continuous Moderate-Intensity Exercise. Am. J. Physiol. Endocrinol. Metab. 2014, 307.

45. Bracken, R.M.; Linnane, D.M.; Brooks, S. Plasma Catecholamine and Nephrine Responses to Brief Intermittent Maximal Intensity Exercise. Amino Acids 2009, 36.

46. Russo, L.; Lumeng, C.N. Properties and Functions of Adipose Tissue Macrophages in Obesity. Immunology 2018, $155,407-417$.

47. Suárez Carmona, W.; Sánchez Oliver, A.; González Jurado, J. Fisiopatología de La Obesidad: Perspectiva Actual. Rev. Chil. Nutr. 2017, 44, 226-233.

48. Borovikova, L.V.; Ivanova, S.; Zhang, M.; Yang, H.; Botchkina, G.I.; Watkins, L.R.; Wang, H.; Abumrad, N.; Eaton, J.W.; Tracey, K.J. Vagus Nerve Stimulation Attenuates the Systemic Inflammatory Response to Endotoxin. Nature 2000, 405.

49. Rosas-Ballina, M.; Olofsson, P.S.; Ochani, M.; Valdés-Ferrer, S.I.; Levine, Y.A.; Reardon, C.; Tusche, M.W.; Pavlov, V.A.; Andersson, U.; Chavan, S.; et al. Acetylcholine-Synthesizing T Cells Relay Neural Signals in a Vagus Nerve Circuit. Science 2011, 334 .

50. Huaizhu Wu, C.M.B. Skeletal Muscle Inflammation and Insulin Resistance in Obesity. J. Clin. Invest. 2017, $127,43$.

51. Hall, J.E.; Jones, D.W.; Kuo, J.J.; da Silva, A.; Tallam, L.S.; Liu, J. Impact of the Obesity Epidemic on Hypertension and Renal Disease. Curr. Hypertens. Rep. 2003, 5.

52. Williams, K.W.; Smith, B.N. Rapid Inhibition of Neural Excitability in the Nucleus Tractus Solitarii by Leptin: Implications for Ingestive Behaviour. J. Physiol. 2006, 573.

53. Saxton, S.N.; Clark, B.J.; Withers, S.B.; Eringa, E.C.; Heagerty, A.M. Mechanistic Links Between Obesity, Diabetes, and Blood Pressure: Role of Perivascular Adipose Tissue. Physiol. Rev. 2019, 99, doi:10.1152/physrev.00034.2018. 